\title{
Homenaje al Dr. Ernst Georg Nauck
}

\author{
ZUÑO BURSTEIN \\ Instituto Medicina Tropical "Daniel A. Carrión”-UNMSM.
}

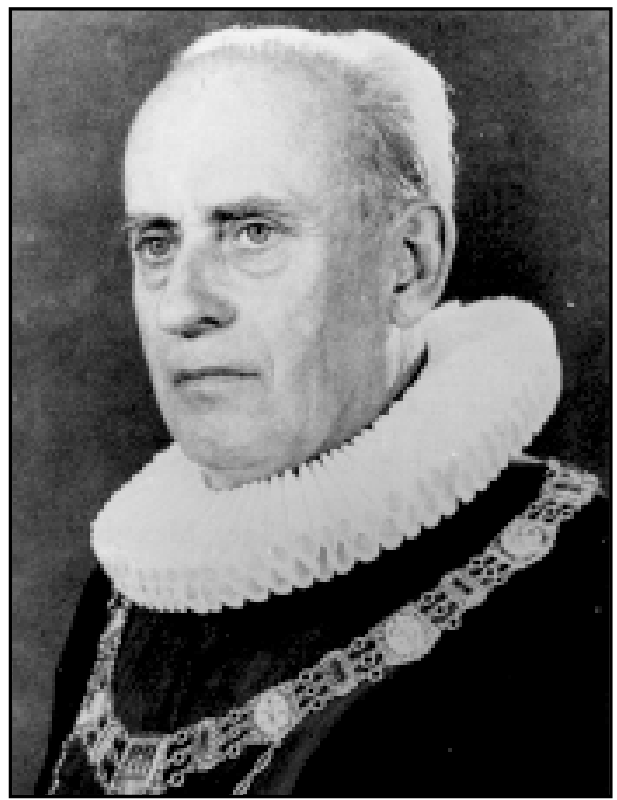

El nombre del Profesor Doctor Ernst G. Nauck estuvo y permanecerá siempre vinculado a la creación del Instituto de Medicina Tropical "Daniel A. Carrión", de la Universidad Nacional Mayor de San Marcos. En esta oportunidad, con motivo de la celebración del $40^{\circ}$ aniversario de la creación de este centro de investigación universitario, se le rinde un homenaje más, en reconocimiento de la decisiva contribución que, en su momento, brindó para la constitución de este instituto en el Perú.

\section{Correspondencia:}

Dr. Zuño Burtein Alva

Instituto de Medicina Tropical "Daniel A. Carrión"

UNMSM - Dermatología Sanitaria.

Jr. José Santos Chocano 199. Urb. San Joaquín

Callao 02, Perú

E-mail:zburstein_2000@yahoo.com
Es necesario recordar que en ese proyecto creativo se contó con la iniciativa y el entusiasta impulso de distinguidas personalidades médicas peruanas, todas, lamentablemente, ya desaparecidas, destacando, entre ellas, el Prof. Dr. Enrique Encinas, desde su laboratorio de investigaciones neuropatológicas, en el Hospital Víctor Larco Herrera y el Prof. Dr. Hugo Pesce, desde la cátedra de Medicina Tropical de la Facultad de Medicina de San Fernando de la Universidad Nacional Mayor de San Marcos, a quienes estamos homenajeando, igualmente, en esta oportunidad.

También hay que mencionar, en forma especial, al Dr. Hugo Lumbreras, gran amigo nuestro, quien, desde el Instituto de Medicina Tropical de Hamburgo, donde se encontraba en ese entonces como becario peruano, y el Dr. 
Victor Manchego, desde su representación diplomática en Bonn, Alemania, hicieron gestiones que permitieron que se hiciese realidad lo que inicialmente fuera el sueño de un grupo de jóvenes científicos peruanos, entusiasmados con el estudio de nuestras enfermedades tropicales, logrando el convenio binacional peruano-alemán, con una importante donación del gobierno de la República Federal de Alemania y la contribución correspondiente, como contraparte, del gobierno peruano, que permitieron la creación de este centro. Lamentablemente, el Dr. Hugo Lumbreras nunca se incorporó al Instituto de Medicina Tropical "Daniel A. Carrión" de la Universidad Nacional Mayor de San Marcos debido a su renuncia a esta casa de estudios con motivo de la creación de la Universidad Peruana Cayetano Heredia, universidad privada, donde creó y fue Director hasta su fallecimiento de otro Instituto de Medicina Tropical en Lima, que lleva el nombre de "Alexander von Humboldt".

El Dr. E. G. Nauck, distinguido profesor universitario alemán, insigne investigador, notable humanista y políglota, que fuera uno de los más destacados representantes de la ciencia alemana en su país y en el extranjero, nació en 1897, en San Petersburgo; su padre fue un médico alemán y su madre báltica. Creció y se educó en la Rusia zarista hasta 1914, época en que se trasladó a Alemania, donde estudió medicina en las universidades de Leipzig y Greifswald. Se graduó en 1920 y durante los tres primeros años fue Ayudante en el Instituto Patológico de un hospital de Berlín. Posteriormente, entra como asistente científico en la Sección de Bacteriología del Instituto de Enfermedades Tropicales de Hamburgo, en aquel entonces dirigido por el Prof, Dr. Bernhard Nocht, discípulo de Robert Koch, y quien lo fundara el año 1900; el Prof. Nocht era, a la sazón, Decano de la Facultad de Medicina y fue, posteriormente, Rector de la universidad.

El Dr. Nauck estuvo de 1924 a 1927 en China, con fines docentes y de investigación; posteriormente, y hasta 1929, dirigió la Sección de Patología del Hospital San Juan de Dios, en San José de Costa Rica; ulteriormente, estuvo en Transcaucasia. En 1934 es nombrado Profesor Extraordinario de la Universidad de Hamburgo, realizando en los años 1936-37, viajes de estudio a Brasil, República Dominicana y Colombia. En 1943, se le encargó interinamente la dirección del Instituto de Medicina Tropical "Bernhard Nocht" de Hamburgo y dos años después, al promovérsele a profesor ordinario de Medicina Tropical en la Universidad de Hamburgo, se le nombra definitivamente como Director de dicho instituto, encargándose de su reorganización y reconstrucción de los severos daños producidos por el cataclismo bélico, haciéndole recobrar en poco tiempo su fama internacional, sin interrumpir su actividad y reanudándose los cursos para médicos alemanes y extranjeros, así como la preparación de enfermeras, ayudantes de laboratorio y sanitarios. En 1953 fue elegido Decano de la Facultad de Medicina y el $1^{\circ}$ de octubre de 1958 es nombrado Rector de la Universidad de Hamburgo, llegando así a la cúspide de su carrera académica. El 31 de marzo de 1963 deja el Instituto de Medicina Tropical, por su jubilación, después de haber forjado durante 20 años la historia de ese alto centro de estudios e investigación.

Se retira a España, donde fallece el 19 de octubre de 1967, en circunstancias en que en el Perú se trabajaba con la idea de comprometerlo para que ayudara, como Director, aprovechando su enorme capacidad y gran experiencia, a reorganizar y poner en marcha el Instituto de Medicina Tropical de la Universidad Nacional Mayor de San Marcos, en el que tanto colaboró para su creación.

En aquel entonces yo desempeñaba el cargo de Director Universitario de Planificación, en una época que nuestra universidad entró en una importante reforma estructural; y este instituto, que inicialmente tenia una organización fraccionada, dependiente de 4 cátedras diferentes de la Facultad de Medicina, fue reorganizado, transformándolo en un importante Centro de 
Investigaciones, con autonomía técnicoadministrativa y directamente dependiente del Rectorado de San Marcos; se tomó entonces la decisión de encomendar al Vicerrector Académico, Dr. Alberto Escobar que, en un viaje que en ejercicio de su cargo realizó a Europa, visitara Hamburgo, con la finalidad de restablecer el convenio interrumpido hacía varios años con el Instituto de Medicina Tropical de Hamburgo y comprometiera al Profesor Nauck para que asumiera la jefatura de este Instituto, asumiendo su reorganización y puesta en marcha con el nuevo ordenamiento establecido. Lamentablemente el Profesor Nauck dejaba de existir en ese entonces.

Sin embargo, la gestión en Hamburgo fue parcialmente exitosa al lograr de las nuevas autoridades del Instituto de Hamburgo el envío de una misión a Lima con la intención de restablecer la ayuda alemana a nuestro Instituto, interrumpida desde la separación y creación de la Universidad privada Cayetano Heredia, con la constitución de otro Instituto de Medicina Tropical en esa Universidad. La parte alemana exigió entonces la unificación de las dos instituciones peruanas para restablecer la colaboración. Esta exigencia fue acogida favorablemente por nosotros y con el Dr. Monge, Rector en aquel entonces de la Universidad Cayetano Heredia, firmamos un convenio de integración funcional para la investigación de las enfermedades tropicales; desgraciadamente, este compromiso no se materializó y tampoco fueron aceptadas otras exigencias que surgieron después, interrumpiéndose desde aquel entonces la relación con el Instituto de Medicina Tropical de Hamburgo.

Los campos principales de actividad del Profesor Dr. Nauck fueron la Dermatología Tropical y la Anatomía Patológica de las enfermedades tropicales, habiendo publicado más de 200 trabajos científicos y participado en innumerables congresos y certámenes en todas partes del mundo, prestando sus conocimientos y ayuda técnica en muchos países. La edición del "Manual de Medicina Tropical" (Lehrbuch der Tropenkrankheiten) con sus colaboradores y la fundación de la importante revista "Medicina Tropical y Parasitología" (Zeitschrift für Tropen-Medizin und Parasitologie) son hitos indelebles de su contribución en la historia de esta rama del conocimiento.

El Dr. Nauck ha recibido numerosas distinciones de instituciones universitarias y estatales en los diferentes países favorecidos por su fructífera actividad. El Perú se vio particularmente honrado con su visita en el año 1957, oportunidad en la que se le distinguió con el título de Catedrático Honorario de la Universidad Nacional Mayor de San Marcos, la más antigua de América, visita durante la que, después de estar en contacto con un grupo de jóvenes investigadores peruanos y apreciar la realidad patológica y la factibilidad de realizar investigaciones en el campo de la Medicina Tropical, tomó la decisión de apoyar la iniciativa de crear, con ayuda alemana, un centro de estudios e investigación en ese campo, haciéndose realidad este proyecto años después.

A mediados de la década de los 50, acogidos por el Prof. Dr. Enrique Encinas en su laboratorio de Investigaciones Neuropatológicas del Hospital Víctor Larco Herrera y con la autorización y complacencia de su Director, don Juan Francisco Valega, extraordinario médico psiquiatra de destacada figuración en la bohemia intelectual limeña, quien, con Enrique Encinas y Hugo Pesce, constituían una trilogía amical de contertulios de excepcional nivel, se congregó un grupo de jóvenes profesionales y estudiantes, estudiosos de la medicina tropical, provenientes de la cátedra de Medicina Tropical de la Facultad de Medicina de San Fernando, que dirigía el Prof. Dr. Hugo Pesce, y de otras instituciones académico científicas. Entre ellos se encontraba el Dr. Hugo Lumbreras, quien fuera enviado por el Prof. Encinas con la beca Alexander Von Humboldt al Instituto de Medicina Tropical de Hamburgo, desde donde gestionó, con la ayuda de Víctor Manchego, el viaje del Prof. Nauck a Lima, comisionado por el gobierno alemán para 
dictaminar sobre la procedencia de la ayuda alemana, mediante un convenio, para la creación de este instituto. Estaban integrando este grupo la doctora Olga Palacios (que fuera posteriormente directora de este instituto por largo tiempo), el que suscribe esta memoria, Dr. Zuño Burstein (actual Profesor Emérito de la Universidad de San Marcos, investigador permanente y varias veces Director interino de esta institución) (ambos fueron enviados por el Prof. Encinas y por el Prof. Hugo Pesce, con becas, a Hamburgo, en misiones especiales de capacitación a un centro especializado virológico y al Instituto de Medicina Tropical, al lado del Prof. Nauck, respectivamente), el Dr. Tejada (actual Director de este instituto fue uno de los más activos colaboradores desde el inicio), el Dr. Oscar Romero (quien fuera después Profesor Principal y Jefe de la Cátedra de Dermatología de la UNMSM.), el Dr. César Náquira (destacado profesor e investigador científico), el Dr. Humberto Guerra (quien fuera después Director del Instituto de Medicina Tropical Alexander Von Humboldt), el Dr. Jorge Montesinos (lamentablemente fallecido tempranamente), la Dra. Bertha Llanos (destacada entomóloga), la Dra. Juana Infantes (distinguida botánica, ya fallecida), la Dra. Juana Arrarte (bióloga, recientemente fallecida), la Dra. Carmen Villanueva (bióloga) y la Dra. Yolanda Lizarazo (bióloga), entre otros.

Este grupo tuvo a su cargo recibir al Prof. Nauck en Lima, en 1957, causando en él la apreciación y la toma de decisión ya referida en beneficio de nuestro país, que competía, en aquel momento, con una alternativa de apoyo alemán a la creación de un importante centro de investigación en Brasil.

El Instituto de Medicina Tropical "Daniel A. Carrión", de la Universidad Nacional Mayor de San Marcos de Lima rinde hoy, nuevamente, un homenaje sincero a esta magna figura de la ciencia universal.

Quiero agregar a título personal, en este homenaje que en representación institucional he ofrecido al Dr. Ernst Nauck, mis expresiones de reconocimiento a esta excepcional personalidad científica alemana y a través de él a todos aquellos intelectuales y científicos representantes de la prestigiada cultura alemana, que en su momento alcanzó los más altos niveles de expresión, tanto en los campos de la filosofía y el arte, como en las ciencias y la tecnología, y que lograron sobrevivir a la masacre desatada en toda Europa, hace sólo 60 años, por las bestiales hordas nazis que asesinaron cobardemente a millones de seres humanos inocentes, provocando desolación, destrucción y muerte, que la humanidad nunca debe olvidar, con un saldo de más de 20 millones de muertos y la demolición casi total de las principales ciudades alemanas, así como de muchas otras en toda Europa.

El Profesor Nauck, al igual que otros que deberían ser considerados como héroes de la resistencia civil a la barbarie, emprendió, con una increíble tenacidad, la reconstrucción de todo el daño provocado por esa insania, sin precedentes históricos y que, felizmente, gracias a la solidez de sus instituciones científicas, éstas fueron parcialmente respetadas.

En el caso del Prof. Nauck, en menos de cinco años, con el cargo de Director que se le otorgó, logró colocar nuevamente en pie su Instituto de Medicina Tropical, uno de los más famosos del mundo, en el alto nivel que siempre ostentó, dando un ejemplo histórico a seguir por nosotros. Tuve la oportunidad, a fines de los años 50, de trabajar como becario del gobierno alemán, al lado del Prof. Nauck, siendo testigo de excepción de su gran condición humana, espíritu pluralista y del gran afecto que tenía a nuestros países, que lo llevó, incluso, a buscar su eterno reposo en tierras hispanas.

A nuestras actuales autoridades universitarias quiero expresarles que, después de décadas de espera, teníamos la justa expectativa de que un Rector, que es un distinguido historiador y un Decano de la Facultad de Medicina, que es un prestigioso académico e investigador científico, 
ambos con indiscutibles valores personales, quebrarían la situación de indiferencia y espantosa precariedad de recursos asignados a la investigación científica, motor de nuestro progreso como país, homologándose, así, con el Prof. alemán que homenajeamos, quien fuera Director de un Instituto, Decano de medicina y Rector de la Universidad de Hamburgo y que, con quizás similares méritos personales que ustedes, logró, gracias a su tenacidad y disciplina, los logros enunciados, en beneficio de su país, superando la peor hecatombe histórica que pasó Alemania.

En cambio, nosotros, con sólo una guerra con Chile hace 125 años, luchamos permanentemente contra nuestra propia inestabilidad institucional, la indiferencia y el olvido y estamos entre los últimos países del planeta en producción científica y marginados del resto del mundo moderno.

En nuestro Instituto colaboran gratuita y generosamente un buen grupo de profesionales altamente calificados, con demostrada emoción social, otorgando servicio asistencial a la comunidad de escasos recursos.

A nuestros amigos representantes de los países del viejo mundo, los exhortamos a volver a darnos la mano como fuera hace ya más de 25 años; y agradecemos la generosa colaboración de la industria farmacéutica que, sensibilizada por nosotros, ha comenzado ya a otorgarse. 